Article

\title{
Music Therapy Self-Care Group for Parents of Preterm Infants in the Neonatal Intensive Care Unit: A Clinical Pilot Intervention
}

\author{
Esteban Roa ${ }^{1,2}$ and Mark Ettenberger $2,3, *$ (D) \\ 1 Berklee College of Music, Boston, MA 02215, USA; eroafuentes@berklee.edu \\ 2 SONO-Centro de Musicoterapia, Bogotá 11021, Colombia \\ 3 Clínica de la Mujer, Bogotá 11021, Colombia \\ * Correspondence: mark.ettenberger@gmx.at; Tel.: +57-311-284-7635
}

Received: 16 November 2018; Accepted: 13 December 2018; Published: 16 December 2018

\begin{abstract}
Background: The parents of preterm infants face major mental health challenges in the Neonatal Intensive Care Unit (NICU). Family-centered music therapy actively integrates and empowers parents in their infants' care. With the aim to better understand and address parental needs separately from their babies' needs, a music therapy (MT) self-care group was implemented as part of clinical practice at the hospital Clínica de la Mujer, in Bogotá, Colombia. Methods: The group was provided for both parents, twice a week, in the NICU. Music guided relaxations, breathing techniques, and self-expression were at the center of the MT group sessions. The parents completed a pre/post self-administered Numeric Rating Scale (NRS), including anxiety levels, stress levels, mood and motivation. Results: The parents highly valued the MT self-care group in the NICU. On average, there was a $37 \%$ improvement in anxiety levels, $28 \%$ improvement in stress levels, and $12 \%$ improvement in mood, restfulness and motivation. Being able to relax, to distract themselves from their worries and having time for themselves are amongst the most frequently mentioned benefits. Conclusions: Addressing parents' needs separately from their babies' treatment, with culturally sensitive interventions aimed at improving parental mental health, is essential for continuing the development of family-centered music therapy interventions in the NICU.
\end{abstract}

Keywords: music therapy; preterm infants; family-centered care; parents; self-care; wellbeing; Neonatal Intensive Care Unit (NICU)

\section{Introduction}

Having a newborn child is seen as a transformational and, often times, positive experience. However, having a preterm baby in the Neonatal Intensive Care Unit (NICU) can interrupt the transition into parenthood and cause parents to feel a surfeit of emotions, often leading to a sense of hopelessness, psychological distress, anxiety and symptoms of depression [1-5]. Uncertainties revolving around the infant's health, being in an intimidating and alien environment, the financial demands of hospitalization, and the physical appearance of the infant can all be potential stressors for the parents, putting their emotional and mental wellbeing at risk [5-7].

Mothers of preterm infants may show long-lasting signs of posttraumatic stress, depressive symptoms, and anxiety [8-10]. If the trauma experienced during the perinatal period is not addressed adequately, it may negatively affect the relationship between the mother and the child, specifically the mother's availability to recognize the infant's cues and needs [11,12]. Recently, fathers have been taking a more active role in the NICU $[13,14]$ and, just like mothers, fathers are susceptible to various common stressors [15]. Having to care for both their infant and their partner, the pressures of keeping up with 
employment obligations and possible tensions related to cultural and societal expectations regarding 'masculinity', or gender roles are some of the primary stressors that are specific to fathers $[13,16-18]$. Unfortunately, follow-up on parental psychological wellbeing during and after hospitalization is not always included in the neonatal care settings. There is a need for culturally appropriate interventions that take into account psychological distress and wellbeing among parents in the NICU $[15,17,19,20]$. Understanding and addressing parents' needs as both connected to and distinct from their babies' needs may help parents not only as individuals, but it may also positively impact their journey towards parenthood and the relationship they foster with their baby.

\section{Family-Centered Care and Family-Centered Music Therapy in the NICU}

Family-Centered Care (FCC) is a growing approach to pediatric health care in which the family is recognized as the patient's primary source of support and as a fundamental part of their wellbeing [21]. The principles of FCC include information sharing, respect and honoring differences, partnership and collaboration, negotiation, and care in the context of the family and community [22]. This approach in health care has become a fundamental pillar in contemporary neonatal care [23] and has been shown to strengthen the parent-infant relationship [9,24], increase the wellbeing of preterm infants [25], and reduce parental stress [26].

Music therapy in the NICU is a well-established field of clinical practice and research [27-29]. Current literature suggests that music therapy is beneficial for both the neonates and caregivers [30-33]. Interventions directed towards the neonate aim to promote physiological and behavioral self-regulation $[31,34]$, feeding success $[31,35,36]$ and improve sleep or quiet alert states [31,37]. The positive impacts of music therapy on parents include relaxation [34], the reduction of anxiety and stress levels [30,31,38], and improved parent-infant bonding [30,33,39-41]. Qualitative analyses show that through the use of music parents can feel empowered by having a more active role in their infants' care [41-43], which is crucial for the transition into parenthood [44,45].

The recent shift in pediatric health care to actively integrate parents in their infants' treatment should also consider their individual wellbeing. Family-centered music therapy in the NICU is rooted in FCC principles and stresses the importance of both infant and parental wellbeing as being essential in neonatal care settings $[30,43,46,47]$. In order to further develop and detect new ways to help mothers and fathers cope with potential stressors and mental health risks, a music therapy self-care group for parents was implemented as part of the ongoing clinical practice at the NICU in the Clínica de la Mujer. This article highlights the development, process, and preliminary results of this clinical pilot intervention.

\section{Materials and Methods}

\subsection{Context and Setting}

The Clínica de la Mujer is one of Bogotá's (the capital of Colombia) most renowned maternity hospitals. Its Level-III NICU has space for 19 incubators located in individual rooms, with a few rooms reserved for twins. Parents have $24-h$ access to the unit and grandparents can visit the babies once a week. Kangaroo care is a standard intervention in the NICU and music therapy is part of an interdisciplinary therapy team, including respiratory therapy, speech and language therapy, nutrition, social work and psychology/psychiatry. FCC principles and a strong commitment to humanized care build the foundations of the hospital's care philosophy. Music therapy is provided twice a week for preterm and critically ill full-term babies and their families, focused primarily on parent-infant bonding, infant self-regulation and parental mental health.

The music therapy self-care group for mothers and fathers was integrated into a music therapy clinical practice as a pilot intervention in July 2018. Initially, the idea for the group developed in response to many mothers' concerns regarding their difficulties during breast milk extraction due to worries about their babies' health and the pressure to produce enough milk. It was hypothesized that a 
music therapy self-care group could help mothers to relax and thus reduce the stress perceived during breast milk extraction. After a few pilot sessions and in discussion with the parents and the health care team, it became clear however that not only mothers but also fathers could benefit from the self-care group. As a result, the group was opened for mothers and fathers in August 2018. With the aim to improve parental wellbeing during the NICU stay, the group is provided twice a week for 15-20 min on Wednesday afternoons and for 30 min on Friday mornings.

\subsection{Music Therapy Self-Care Group: Procedure and Interventions}

The group takes place in the NICU's breast milk extraction room before mothers are scheduled for their next time slot. Although participation in the music therapy self-care group is voluntary, the nursing and medical teams highly encourage both mothers and fathers to attend. The group usually starts with a short verbal introduction with the purpose of explaining the objectives and procedures for the new participants and to quickly assess current parents' moods or any specific stressors.

Live music therapy is at the center of the interventions. The music therapist regularly uses a nylon-string guitar, their voice, shakers, an ocean drum, and a 'Samafón' as the principal instruments. The 'Samafón' is an instrument that is shaped similar to a lyre, but instead of the strings, five hollow metal tubes hang from the top to the base of the instrument and are connected to each other with threads. Depending on the length of the tubes, notes are lower or higher and the instrument is normally tuned in variations of the pentatonic scales. The tubes are played either individually or quickly, one after another, with a mallet used for singing bowls and the sound is long-lasting. Additionally, the instrument can be rotated easily, holding it with one hand, creating ripples of sounds that project themselves in all directions. Short musical games with shakers, voices or movements serve as 'ice-breakers', seeking to activate the participants at the beginning of the session. Then, the music therapist provides verbal relaxation prompts focused on deep breathing, imagery (i.e., visualizing a place where participants feel safe and comfortable, or evoking a particular landscape, such as standing on a mountain top and looking over the horizon or sitting on the beach and contemplating the movement of the waves), and/or subtle movements with the objective to foster body awareness and to make conscious current moods, thoughts, or emotions. Subsequently, live music is provided, inviting parents to breathe with the music. Alternatively, parents are encouraged to use their voices with the music by either humming or singing vowels or closed consonants in order to achieve increased lengths of exhalation and to creatively explore their musicality.

Although there is debate on what music is best for relaxation [46], the music during the interventions is typically improvised and based on elements such as a slow tempo, repetition, and subtle melodic and harmonic variations or modulations. Often, chord intervals clearly indicating major or minor tonalities (i.e., major or minor thirds) are substituted with sus ${ }^{9}$ or sus ${ }^{4}$ chords, leaving it open to the music therapist's clinical improvisation skills to modulate between major or minor tonalities.

Once the intervention concludes, parents verbally reflect upon their experiences, thoughts, and feelings during the group session. The music therapist discusses music-assisted self-care techniques that participants can use in their own time. Such techniques include deep breathing techniques with music or voice, the use of recorded music for relaxation, and information sharing between parents.

\subsection{Evaluation and Measurements}

To evaluate the clinical pilot program and to better understand the potential benefits of the music therapy self-care group for parents in the NICU, the music therapy team designed a self-administered pre/post Numeric Rating Scale (NRS). It is important to highlight that the results gathered from the NRS are strictly used to evaluate the clinical pilot program and are not used for research purposes. The scale aims to detect changes in the perceived levels of anxiety, stress, and wellbeing before and after the music therapy intervention. An 'additional comments' section on the post-intervention sheet provides the opportunity for parents to share more personalized experiences and recommendations in regards to the group. Figure 1 shows the NRS that is currently used. 


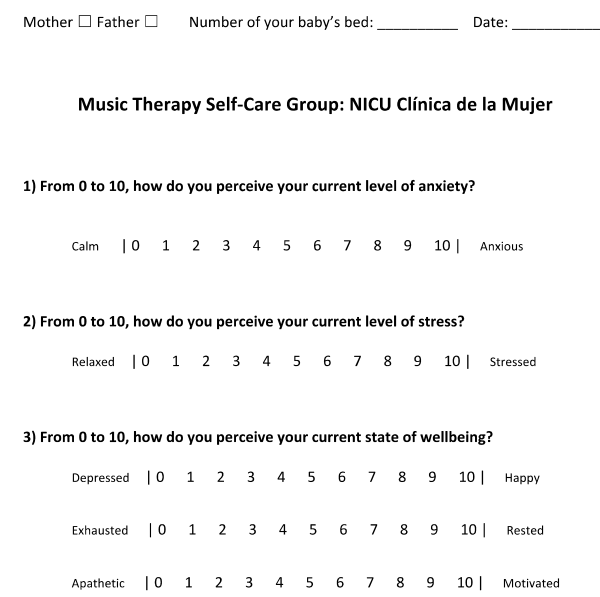

(a)

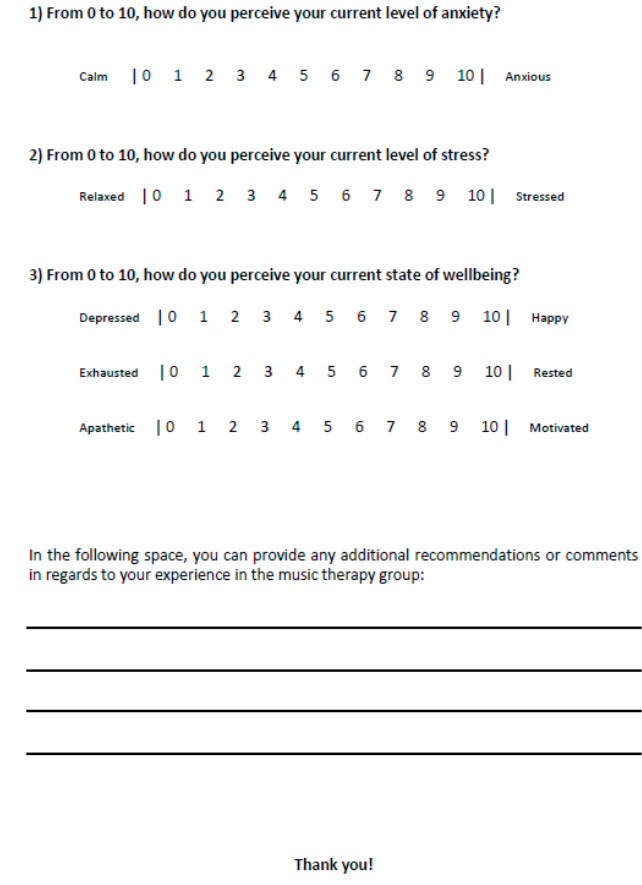

(b)

Figure 1. This figure shows the Numeric Rating Scale (NRS) the music therapy team designed to evaluate the clinical pilot program. (a) This is the pre-intervention sheet. Participants are given a few minutes prior to the intervention in order to fill it out. As shown above, the music therapy team considered anxiety, stress, and three areas of wellbeing, including mood, restfulness, and motivation. (b) This is the post-intervention sheet. The only difference is the 'additional comments' section at the bottom of the page. Participants are given a few minutes after the intervention in order to fill it out.

Parents are assured that their names and personal information are not used during the evaluation of the program. In addition to the NRS, a few semi-structured interviews were conducted with the participating parents to further understand their lived experiences with music therapy.

\section{Results}

As stated above, the music therapy self-care group took place twice a week. However, due to time restrictions on one of the days, data collection only took place before and after the thirty-minute sessions on Fridays. While the evaluation of the group is part of the clinical practice, it is hoped that the current data collection will help in the establishment of a research protocol in the near future. Table 1 shows the basic features of the group.

Table 1. Basic features of the music therapy self-care group since its implementation in July 2018 to November 2018.

\begin{tabular}{cccc}
\hline Total Number of Sessions & Total Number of Participants & Total Number of Mothers & Total Number of Fathers \\
\hline 30 & 122 & 106 & 16 \\
\hline
\end{tabular}

The results obtained with the NRS indicate a positive effect of the music therapy self-care group on parents' perceived anxiety and stress levels, and on their mood, restfulness, and motivation. Table 2 shows the mean scores for the pre- and post-intervention.

Figure 2 shows the results as bar charts. On average, there is a 37\% improvement in anxiety levels, a $28 \%$ improvement in stress levels, a $6 \%$ improvement in mood, a $20 \%$ improvement in restfulness, and a $9 \%$ improvement in motivation. Being able to relax, to distract themselves from their worries 
and to have time for themselves are amongst the most frequently mentioned benefits parents left in the 'additional comments' section.

Table 2. The mean scores for anxiety and stress levels, mood, restfulness and motivation before and after the music therapy self-care group.

\begin{tabular}{cccccc}
\hline Intervention & Anxiety Levels & Stress Levels & Mood & Restfulness & Motivation \\
\hline Pre-intervention & 5.8 & 5.2 & 7.1 & 4.8 & 7.2 \\
Post-intervention & 2.1 & 2.4 & 7.7 & 6.8 & 8.1 \\
\hline
\end{tabular}

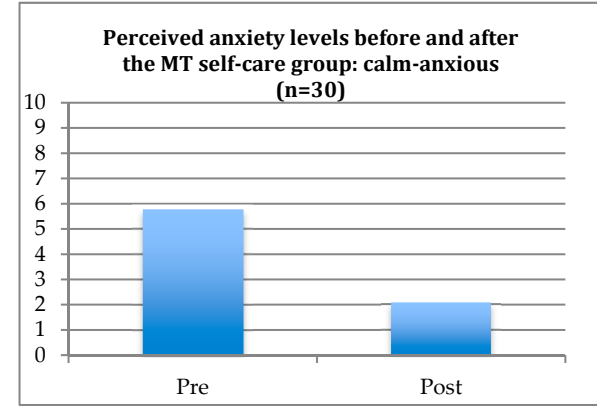

(a)

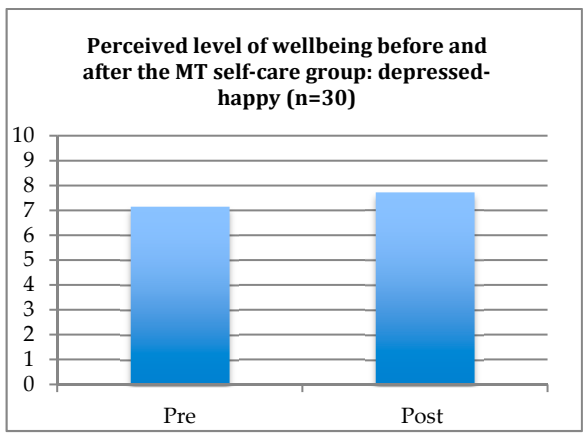

(c)

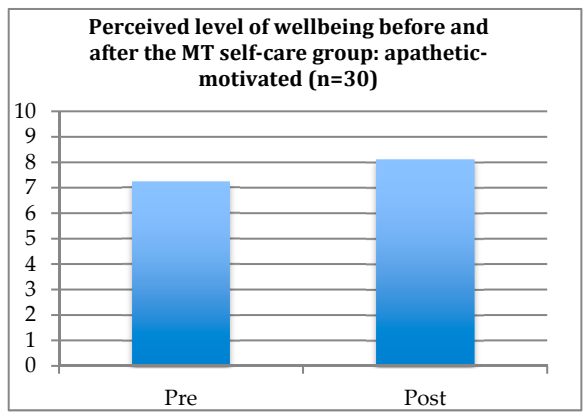

(e)

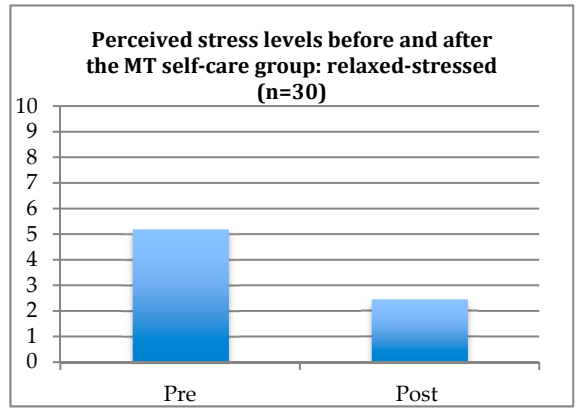

(b)

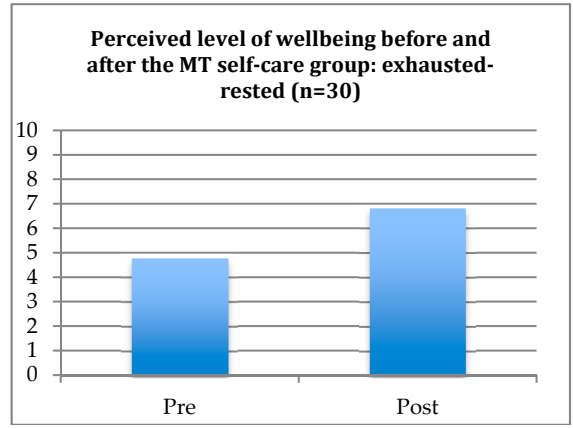

(d)

Figure 2. This figure shows the bar charts of the pre- and post-intervention results obtained with the NRS. Please note that the NRS was introduced at a later point, after the start of the clinical pilot program. This is why the data of 30 participants were collected via the NRS, but there were 122 participants in total. (a) This bar chart shows the perceived level of anxiety before and after the group sessions. A lower score indicates less perceived anxiety. (b) This bar chart shows the perceived level of stress before and after the group sessions. A lower score indicates less perceived stress. (c) This bar chart shows the perceived level of mood before and after the group sessions. A higher score indicates a better perceived mood. (d) This bar chart shows the perceived level of restfulness before and after the group sessions. A higher score indicates a better perceived feeling of restfulness. (e) This bar chart shows the perceived level of motivation before and after the group sessions. A higher score indicates a better perceived motivation. 


\section{Limitations}

Although the evaluation of the music therapy self-care group was not part of the research protocol, the clinical pilot intervention faced the following limitations that should be considered for future investigations:

- The sessions take place in the breast milk extraction room between scheduled milk extraction time slots. Due to its size, it is currently the only available space in the NICU appropriate for group interventions. However, since breast milk extraction usually takes place continuously throughout the day, this caused difficulties with respect to the time restriction for the group on one of the days (Wednesday afternoon).

- The clinical pilot program aims to address the needs of both mothers and fathers. Bearing in mind the cultural norms, perceptions on gender roles, and employment obligations in Colombian society, there were not as many fathers present as mothers throughout the pilot program. Nonetheless, participating fathers regularly express having a positive experience with the group and encouraged that it be formalized in NICU care.

- Since mothers do not always schedule the same time slot for breast milk extraction and kangaroo care with their babies, participation in the group session was inconsistent. Some mothers joined the group several times, but others participated just once. To better assess the outcomes, it is suggested that the participants have a consistent and scheduled attendance for the music therapy self-care group.

- The music therapy team designed the NRS which was used to evaluate the clinical pilot intervention based on the experiences in clinical practice; it is not a standardized assessment tool and has not been validated. Nevertheless, it seems to be an intuitive and easily applicable tool to quickly assess some of the most important domains of parental wellbeing and the parents reported no difficulties in understanding the NRS.

\section{Discussion and Conclusions}

Parents in the NICU face many challenges that may have potential negative and long-lasting mental health implications. These challenges put not only the individual wellbeing of mothers and fathers at risk, but might also affect the evolving relationship with their baby [1,10-12,48,49]. Parents frequently communicate the need to access tools to better cope with the difficulties that a hospitalization in the NICU can imply and those parents who are provided with appropriate strategies feel empowered, which in turn can positively affect their personal wellbeing and their babies' development [50].

Despite the recent shift in NICU music therapy towards a more inclusive approach of mothers and fathers, studies that focus on relevant parental outcomes are still scarce [51]. Parental wellbeing is also influenced by many different factors, making it difficult to define and measure [52]. The music therapy self-care group at the Clínica de la Mujer was implemented to consciously try to address some of the most common parental stressors mentioned in pediatric health care literature [50] and to focus on parents' needs as individuals. The sessions aimed at providing a space for parents to work on their personal wellbeing using simple and transferable tools relevant for resilience and coping. The results gathered from the NRS are promising and indicate that mothers and fathers experience a decrease in perceived levels of anxiety and stress, and an improvement in mood, relaxation and restfulness after the intervention.

"A state of wellbeing is easily achieved with music therapy. Being in the NICU is stressful, but it becomes tolerable with this type of support." (A participating mother)

Although no data were collected regarding our initial motive to reduce maternal stress and anxiety during breast milk extraction, a limited number of articles report a positive impact of recorded music on breast milk quantity and quality $[53,54]$. An improved relaxation response in mothers has been 
discussed as a potential mechanism in both of the aforementioned studies, and is in-line with the already documented anxiolytic and stress-reducing effects of music and music therapy interventions in the NICU [27-30,34,55,56]. Thus, a positive impact of the music therapy self-care group on maternal breast milk extraction seems to be a feasible hypothesis that needs to be investigated with a formal research protocol in the future.

"It is a great space because it allows us to rest and disconnect from the situation we are going through."

(A participating father)

For this clinical pilot intervention, live music was considered the best practice due to the flexibility and ability to adapt the music depending on the parents' responses and current needs. Moreover, live music allows for a group dynamic in which participants can interact and share their experiences with one another. Considering that information sharing is at the core of the FCC principles [21,22], the music therapist regularly encourages and facilitates participants to share their experiences after the intervention and to use the space to build a support system amongst themselves. The time allocated for reflection and discussion after the intervention allows parents to share not only their current struggles and difficulties, but also ways to cope with them. Furthermore, considering the 'collective' nature of Colombian society, the active and interactive participation of parents was considered to be more culturally appropriate than individually using recorded music.

"It is a relaxing activity. It should be done more frequently. It allows us to alleviate the stress from this situation." (A participating mother)

This article highlights the impact of a music therapy self-care group on parental wellbeing in the NICU. The preliminary findings from this clinical pilot intervention indicate that this may be an appropriate intervention to help parents with stress reduction, coping, and relaxation. The pilot program aims to develop a research protocol in the near future to better evaluate the impact of the music therapy self-care group on parental mental health and on mothers' breast milk extraction. Addressing parents' needs separately from their babies' treatment, with culturally sensitive interventions aimed at improving parental mental health, is essential for continuing the development of family-centered music therapy in the NICU.

Author Contributions: All authors declare equal contribution for this article. Conceptualization, methodology, implementation, analysis, and draft preparation: E.R. \& M.E. Supervision, review \& editing: M.E.

Funding: This research received no external funding.

Acknowledgments: The authors are thankful to all the parents participating in the group sessions and to the NICU staff and the hospital's administration team of the Clínica de la Mujer for supporting this initiative.

Conflicts of Interest: The authors declare no conflict of interest.

\section{References}

1. Aagard, H.; Hall, E.O.C. Mothers' experiences of having a preterm infant in the neonatal care unit: A meta-synthesis. J. Pediatr. Nurs. 2008, 23, 26-36. [CrossRef] [PubMed]

2. Carson, C.; Redshaw, M.; Gray, R.; Quigley, M.A. Risk of psychological distress in parents of preterm children in the first year: Evidence from the UK Millennium Cohort Study. BMJ Open 2015, 5, e007942. [CrossRef] [PubMed]

3. Davis, L.; Edwards, H.; Mohay, H.; Wollin, J. The impact of very premature birth on the psychological health of mothers. Early Hum. Dev. 2003, 73, 61-70. [CrossRef]

4. Meijssen, D.E.; Wolf, M.J.; Koldewijn, K.; van Wassenaer, A.G.; Kok, J.H.; Van Baar, A.L. Parenting stress in mothers after very preterm birth and the effect of the Infant Behavioural Assessment and Intervention Program. Child. Care Health Dev. 2011, 37, 195. [CrossRef] [PubMed]

5. Singer, L.T.; Salvator, A.; Guo, S.; Collin, M.; Lilien, L.; Baley, J. Maternal Psychological Distress and Parenting Stress After the Birth of a Very Low-Birth-Weight Infant. JAMA 1999, 281, 799-805. [CrossRef] [PubMed] 
6. Miles, M.S.; Funk, S.G.; Kasper, M.A. The neonatal intensive care unit environment: Sources of stress for parents. AACN Clin. Issues Crit. Care Nurs. 1991, 2, 346-354. [CrossRef] [PubMed]

7. Stefana, A.; Padovani, E.M.; Biban, P.; Lavelli, M. Experiences with their preterm babies admitted to neonatal intensive care unit: A multi-method study. J. Adv. Nurs. 2018, 74, 1090-1098. [CrossRef]

8. Kersting, A.; Dorsch, M.; Wesselmann, U.; Lüdorff, K.; Witthaut, J.; Ohrmann, P.; Arolt, V. Maternal posttraumatic stress response after the birth of a very low-birth-weight infant. J. Psychosom. Res. 2004, 57, 473-476. [CrossRef]

9. Jotzo, M.; Poets, C.F. Helping Parents Cope with the Trauma of Premature Birth: An Evaluation of a Trauma-Preventive Psychological Intervention. Pediatrics 2005, 115, 915-919. [CrossRef]

10. Hagan, R.; Evans, S.F.; Pope, S. Preventing postnatal depression in mothers of very preterm infants: A randomised controlled trial. BJOG Int. J. Obstetr. Gynaecol. 2004, 111, 641-647. [CrossRef]

11. Muller-Nix, C.; Forcada-Guex, M.; Pierrehumbert, B.; Jaunin, L.; Borghini, A.; Ansermet, F. Prematurity, maternal stress and mother-child interactions. Early Hum. Dev. 2004, 79, 145-158. [CrossRef] [PubMed]

12. Whitfield, M.F. Psychosocial effects of intensive care on infants and families after discharge. Semin. Neonatol. 2003, 8, 185-193. [CrossRef]

13. Mondanaro, J.F.; Ettenberger, M.; Park, L. Mars Rising: Music Therapy and the Increasing Presence of Fathers in the NICU. Music Med. 2016, 8, 96-107.

14. Arockiasamy, V.; Holsti, L.; Albersheim, S. Fathers' experiences in the neonatal intensive care unit: A search for control. Pediatrics 2008, 121, 215-222. [CrossRef] [PubMed]

15. Garten, L.; Nazary, L.; Metze, B.; Bührer, C. Pilot study of experiences and needs of 111 fathers of very low birth weight infants in a neonatal intensive care unit. J. Perinatol. 2013, 33, 65-69. [CrossRef] [PubMed]

16. Hugill, K.; Letherby, G.; Reid, T.; Lavender, T. Experiences of fathers shortly after the birth of their preterm infants. J. Obstetr. Gynecol. Neonatal Nurs. 2013, 42, 655-663. [CrossRef]

17. Sloan, K.; Rowe, J.; Jones, L. Stress and coping in fathers following the birth of a preterm infant. J. Neonatal Nurs. 2008, 14, 108-115. [CrossRef]

18. Ahn, Y.-M.; Kim, N.-H. Parental Perception of Neonates, Parental Stress and Education for NICU Parents. Asian Nurs. Res. 2007, 1, 199-210. [CrossRef]

19. Fabiyi, C.; Rankin, K.; Norr, K.; Shapiro, N.; White-Traut, R. Anxiety among Black and Latina Mothers of Premature Infants at Social-Environmental Risk. Newborn Infant Nurs. Rev. 2012, 12, 132-140. [CrossRef]

20. Turan, T.; Başbakkal, Z.; Ozbek, S. Effect of nursing interventions on stressors of parents of premature infants in neonatal intensive care unit. J. Clin. Nurs. 2008, 17, 2856-2866. [CrossRef]

21. Committee on Hospital Care; American Academy of Pediatrics. Family-centered care and the pediatrician's role. Pediatrics 2003, 112 Pt 1, 691-697. [CrossRef]

22. Kuo, D.Z.; Houtrow, A.J.; Arango, P.; Kuhlthau, K.A.; Simmons, J.M.; Neff, J.M. Family-centered care: Current applications and future directions in pediatric health care. Matern. Child. Health J. 2012, 16, $297-305$. [CrossRef] [PubMed]

23. Gooding, J.S.; Cooper, L.G.; Blaine, A.I.; Franck, L.S.; Howse, J.L.; Berns, S.D. Family support and family-centered care in the neonatal intensive care unit: Origins, advances, impact. Semin. Perinatol. 2011, 35, 20-28. [CrossRef] [PubMed]

24. Cooper, L.G.; Gooding, J.S.; Gallagher, J.; Sternesky, L.; Ledsky, R.; Berns, S.D. Impact of a family-centered care initiative on NICU care, staff and families. J. Perinatol. 2007, 27 (Suppl. 2), 32-37. [CrossRef] [PubMed]

25. Van Riper, M. Family-provider relationships and well-being in families with preterm infants in the NICU. Heart Lung J. Crit. Care 2001, 30, 74-84. [CrossRef] [PubMed]

26. Meyer, E.C.; Coll, C.T.; Lester, B.M.; Boukydis, C.F.; McDonough, S.M.; Oh, W. Family-based intervention improves maternal psychological well-being and feeding interaction of preterm infants. Pediatrics 1994, 93, 241-246.

27. Haslbeck, F.B. Music therapy for premature infants and their parents: An integrative review. Nord. J. Music Ther. 2012, 21, 203-226. [CrossRef]

28. Standley, J. Music therapy research in the NICU: An updated meta-analysis. Neonatal Netw. 2012, 31, 311-316. [CrossRef]

29. Bieleninik, Ł.; Ghetti, C.; Gold, C. Music Therapy for Preterm Infants and Their Parents: A Meta-analysis. Pediatrics 2016, 138. [CrossRef] 
30. Ettenberger, M.; Cárdenas, C.R.; Parker, M.; Odell-Miller, H. Family-centred music therapy with preterm infants and their parents in the Neonatal Intensive Care Unit (NICU) in Colombia-A mixed-methods study. Nord. J. Music Ther. 2017, 26, 207-234. [CrossRef]

31. Loewy, J.; Stewart, K.; Dassler, A.-M.; Telsey, A.; Homel, P. The Effects of Music Therapy on Vital Signs, Feeding, and Sleep in Premature Infants. Pediatrics 2013, 131, 902-918. [CrossRef] [PubMed]

32. Loewy, J. NICU music therapy: Song of kin as critical lullaby in research and practice. Ann. N. Y. Acad. Sci. 2015, 1337, 178-185. [CrossRef] [PubMed]

33. Ettenberger, M.; Odell-Miller, H.; Cárdenas, C.; Serrano, S.; Parker, M.; Camargo Llanos, S. Music Therapy With Premature Infants and Their Caregivers in Colombia-A Mixed Methods Pilot Study Including a Randomized Trial. Voices World Forum Music Ther. 2014, 14. [CrossRef]

34. Teckenberg-Jansson, P.; Huotilainen, M.; Pölkki, T.; Lipsanen, J.; Järvenpää, A.-L. Rapid effects of neonatal music therapy combined with kangaroo care on prematurely-born infants. Nord. J. Music Ther. 2011, 20, 22-42. [CrossRef]

35. Standley, J.M. The effect of music-reinforced nonnutritive sucking on feeding rate of premature infants. J. Pediatr. Nurs. 2003, 18, 169-173. [CrossRef] [PubMed]

36. Vianna, M.; Barbosa, A.P.; Carvalhaes, A.S.; Cunha, A. Music therapy may increase breastfeeding rates among mothers of premature newborns: A randomized controlled trial. Jornal de Pediatria 2011, 87, $206-212$. [CrossRef] [PubMed]

37. Olischar, M.; Shoemark, H.; Holton, T.; Weninger, M.; Hunt, R.W. The influence of music on a EEG activity in neurologically healthy newborns $\geq 32$ weeks' gestational age. Acta Paediatr. 2011, 100, 670-675. [CrossRef]

38. Cevasco, A.M. The effects of mothers' singing on full-term and preterm infants and maternal emotional responses. J. Music Ther. 2008, 45, 273-306. [CrossRef]

39. Walworth, D. Effects of Developmental Music Groups for Parents and Premature or Typical Infants Under Two Years on Parental Responsiveness and Infant Social Development. J. Music Ther. 2009, 46, 32-52. [CrossRef]

40. Haslbeck, F.B. The interactive potential of creative music therapy with premature infants and their parents: A qualitative analysis. Nord. J. Music Ther. 2014, 23, 36-70. [CrossRef]

41. McLean, E. Fostering intimacy through musical beginnings: Exploring the application of communicative musicality through the musical experience of parents in a neonatal intensive care unit. Voices World Forum Music Ther. 2016, 16. Available online: https://voices.no/index.php/voices/article/view/874/721 (accessed on 30 November 2018). [CrossRef]

42. Palazzi, A.; Meschini, R.; Piccinini, C.A. Music therapy intervention for the mother-preterm infant dyad: Evidence from a case study in a Brazilian NICU. Voices World Forum Music Ther. 2017, 17. Available online: https://voices.no/index.php/voices/article/view/916 (accessed on 30 November 2018). [CrossRef]

43. Shoemark, H.; Dearn, T. Keeping Parents at the Centre of Family Centred Music Therapy with Hospitalized Infants. Aust. J. Music Ther. 2008, 19, 3-24.

44. Hutchinson, S.W.; Spillett, M.A.; Cronin, M. Parents' Experiences during their Infant's Transition from Neonatal Intensive Care Unit to Home: A Qualitative Study. Qual. Rep. 2012, 17, 1-20.

45. McLean, E.; McFerran Skewes, K.; Thompson, G.A. Parents' musical engagement with their baby in the neonatal unit to support emerging parental identity: A grounded theory study. J. Neonatal Nurs. 2018. [CrossRef]

46. Haslbeck, F. Three little wonders. Music Therapy with families in neonatal care. In Music Therapy with Families; Lindhal, S., Ed.; Jessica Kingsley Publishers: London, UK, 2016; pp. 19-44.

47. Ettenberger, M. Music therapy in the neonatal intensive care unit: Putting the families at the centre of care. Br. J. Music Ther. 2017, 31, 12-17. [CrossRef]

48. Carter, J.D.; Mulder, R.T.; Darlow, B.A. Parental stress in the NICU: The influence of personality, psychological, pregnancy and family factors. Person. Ment. Health 2007, 1, 40-50. [CrossRef]

49. Pal, S.; Alpay, L.; Steenbrugge, G.; Detmar, S. An Exploration of Parents' Experiences and Empowerment in the Care for Preterm Born Children. J. Child. Fam. Stud. 2014, 23, 1081-1089. [CrossRef]

50. Melnyk, B.M.; Alpert-Gillis, L.; Feinstein, N.F.; Crean, H.F.; Johnson, J.; Fairbanks, E.; Small, L.; Rubenstein, J.; Slota, M.; Corbo-Richert, B. Creating opportunities for parent empowerment: Program effects on the mental health/coping outcomes of critically ill young children and their mothers. Pediatrics 2004, 113, e597-e607. [CrossRef] 
51. Ettenberger. Family-Centred Music Therapy in the Neonatal Intensive Care Unit (NICU): Key concepts, research and examples of clinical practice. In Music Therapy for Premature and Newborn Infants, 2nd ed.; Nöcker-Ribaupierre, M., Ed.; Barcelona Publishers: Gilsum, NH, USA, 2018; in press.

52. Longo, Y.; Coyne, I.; Joseph, S. The Scales of general well-being. Person. Individ. Differ. 2017, 109, 148-159. [CrossRef]

53. Keith, D.R.; Weaver, B.S.; Vogel, R.L. The effect of music-based listening interventions on the volume, fat content, and caloric content of breast milk-produced by mothers of premature and critically ill infants. Adv. Neonatal Care 2012, 12, 112-119. [CrossRef] [PubMed]

54. Ak, J.; Lakshmanagowda, P.B.; G C M, P.; Goturu, J. Impact of music therapy on breast milk secretion in mothers of premature newborns. J. Clin. Diagn. Res. JCDR 2015, 9, 04-06. [CrossRef] [PubMed]

55. Lai, H.-L.; Chen, C.-J.; Peng, T.-C.; Chang, F.-M.; Hsieh, M.-L.; Huang, H.Y.; Chang, S.-H. Randomized controlled trial of music during kangaroo care on maternal state anxiety and preterm infants' responses. Int. J. Nurs. Stud. 2006, 43, 139-146. [CrossRef] [PubMed]

56. Schlez, A.; Litmanovitz, I.; Bauer, S.; Dolfin, T.; Regev, R.; Arnon, S. Combining Kangaroo Care and Live Harp Music Therapy in the Neonatal Intensive Care Unit Setting. Isr. Med. Assoc. J. 2011, 13, 354-358. [PubMed]

(C) 2018 by the authors. Licensee MDPI, Basel, Switzerland. This article is an open access article distributed under the terms and conditions of the Creative Commons Attribution (CC BY) license (http:/ / creativecommons.org/licenses/by/4.0/). 